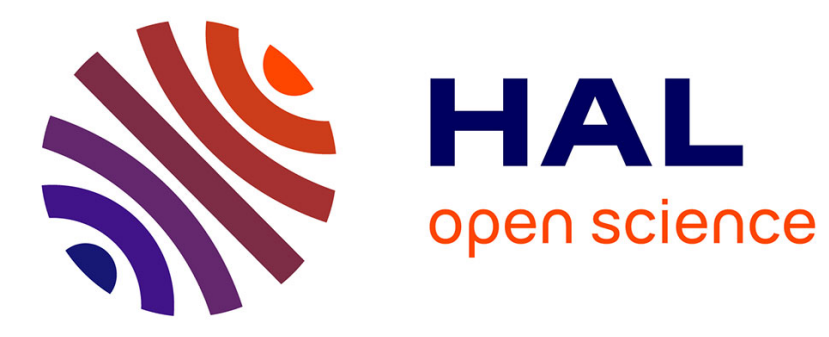

\title{
Platinum metals and microstructure in magnetic deep sea cosmic spherules
}

\author{
Ph. Bonté, C. Jéhanno, M. Maurette, D. E Brownlee
}

\section{To cite this version:}

Ph. Bonté, C. Jéhanno, M. Maurette, D. E Brownlee. Platinum metals and microstructure in magnetic deep sea cosmic spherules. Journal of Geophysical Research, 1987, 92 (B4), pp.E641-E648. 10.1029/JB092iB04p0E641 . hal-03545787

\section{HAL Id: hal-03545787 \\ https://hal.science/hal-03545787}

Submitted on 27 Jan 2022

HAL is a multi-disciplinary open access archive for the deposit and dissemination of scientific research documents, whether they are published or not. The documents may come from teaching and research institutions in France or abroad, or from public or private research centers.
L'archive ouverte pluridisciplinaire HAL, est destinée au dépôt et à la diffusion de documents scientifiques de niveau recherche, publiés ou non, émanant des établissements d'enseignement et de recherche français ou étrangers, des laboratoires publics ou privés. 


\title{
Platinum Metals and Microstructure in Magnetic Deep Sea Cosmic Spherules
}

\author{
Ph. Bonté AND C. JÉHANNO
}

Centre des Faibles Radioactivités, Laboratoire Mixte CEA-CNRS, Gif-sur-Yvette, France

\section{MAuretTe}

Laboratoire René Bernas, Orsay, France

\author{
D. E. BROWNLEE
}

Department of Astronomy, University of Washington, Seattle

\begin{abstract}
Instrumental neutron activation analysis was used to determine the concentrations of $\mathrm{Ir}, \mathrm{Fe}, \mathrm{Ni}, \mathrm{Co}$, $\mathrm{Cr}$, and Sc in 16 "iron" and 8 "chondritic" magnetic deep sea spherules with sizes of about $200 \mu \mathrm{m}$. With the exception of two iron spheres, high iridium concentrations were found in each sphere, thus confirming their extraterrestrial origin. Moreover, the "depth profile" of the residual mass of iridium was monitored in individual spheres by comparing the variations of the intensities of the $\gamma$ ray lines of iridium, cobalt, and iron during a very gradual sequential polishing. Each sharp but partial discontinuity, observed only in the Ir profiles, reflects the intersection of a polished section with a tiny Ir-rich nugget. These profiles show that such nuggets are mucb more common in both the iron and the chondritic spheres than previously thought. We found new types of disequilibrated clusters of micrometer-sized nuggets of platinum metals. All types of nuggets, which were characterized with a scanning electron microscope and an energy dispersive $X$ ray spectrometer, seem to be associated with magnetite. The compositions of the nuggets, as well as the fractionation patterns for $\mathrm{Ir}, \mathrm{Fe}, \mathrm{Ni}, \mathrm{Co}$, and $\mathrm{Sc}$ in the spheres, suggest that most of the Ir-rich iron spheres originate from iron-rich bodies.
\end{abstract}

\section{INTRODUCTION}

Collections of magnetic spherules ("spheres") extracted from deep sea sediments contain a major component of extraterrestrial spheres with very specific composition and textural features; these include: iron spheres, composed of $\mathrm{Fe} / \mathrm{Ni}$ oxides, and chondritic spheres, i.e., stony spheres showing a chondritic composition of major elements [Brownlee, 1981]. Some of the characteristic textural features of the spheres have been reported in Figure 1.

Instrumental Neutron Activation Analysis (INAA) of individual deep sea spheres has already been reported; however, no correlated electron microscope and/or electron microprobe study of them was carried out. Ganapathy [1983] compared the INAA analysis of eight glassy spheres collected at the site of the Tunguska event with those of eight chondritic spheres magnetically extracted from deep sea sediments. Yamakoshi [1985] reported IN AA data for about 400 deep sea iron spheres that were characterized only by their size, ranging from $20 \mu \mathrm{m}$ up to $1000 \mu \mathrm{m}$. He thus noted the trend of higher Ir concentrations in the smaller iron spheres.

On the other hand, by relying on both a painstaking sequential polishing of iron and chondritic deep sea spheres followed by a direct examination with a scanning electron microscope (SEM) equipped with an energy dispersive $X$ ray system (EDS), Brownlee et al. [1984] reported the discovery of beads or "nuggets" of platinum metals that they found in iron but not in chondritic deep sea spheres. They concluded that nuggets were formed by settling in their host iron spheres. These iron spheres in turn were subsequently ejected as "globules" from melted parent bodies with a chondritic composition.

Copyright 1987 by the American Geophysical Unıon.

Paper number 6B7207.

0148-0227/87/006B-7207\$05.00
In this paper we combine for the first time these two different analytical approaches (i.e., bulk INAA and SEM + EDS analysis), as well as the use of a sequential polishing. Our objective is to further characterize the distribution of platinum metals in individual deep sea cosmic spheres and to correlate these distributions with the microstructure of the spheres and the concentration of other siderophile $(\mathrm{Ni}, \mathrm{Co}$, and $\mathrm{Cr}$ ) and lithophile ( $\mathrm{Cr}$ and $\mathrm{Sc}$ ) elements. The important work of Raisbeck et al. [1984, 1985] has already demonstrated that the parent bodies of a vast majority of the cosmic deep sea spheres are constituent particles of the micrometeorite flux. Thus the present work should help in understanding how the characteristics of the cosmic spheres reflect those of their initial micrometeorite parent bodies in space, after a "reprocessing" resulting from ablation in the atmosphere and terrestrial weathering.

\section{EXPERIMENTAL MEȚHODS}

The cosmic spherules analyzed in this work were extracted by magnetic raking from west Pacific surface clays $0-100,000$ years old found at depths $\sim 5000 \mathrm{~m}$ in the Mariana Trough. We analyzed 16 "iron" and 8 "stony" particles in the 100 to $400 \mu \mathrm{m}$ size fraction, all showing spherical shape already suggesting a melting by ablation in the atmosphere. Only the stony spheres were further preselected by checking with the EDS that their major element composition $(\mathrm{Mg}, \mathrm{Al}, \mathrm{Si}, \mathrm{Ca}, \mathrm{Fe})$ was roughly chondritic.

Our experimental procedure includes the following successive steps: First, the two types of spheres were enclosed in ultrapure quartz containers. They were then irradiated in the OSIRIS reactor (5 hours; flux: $1.24 \times 10^{14} \mathrm{n} / \mathrm{cm}^{2} / \mathrm{s}$ ) at Pierre Süe Laboratory. Standards, including USGS rock $\mathrm{Al}$ and MAGl, and a $0.80 \mathrm{mg}$ chip of an aluminium wire with $1 \mathrm{ppm}$ Ir (prepared by A. A. Samadi), were irradiated in the same rabbit. After removal each sphere was mounted in epoxy resin, and the $\gamma$ 

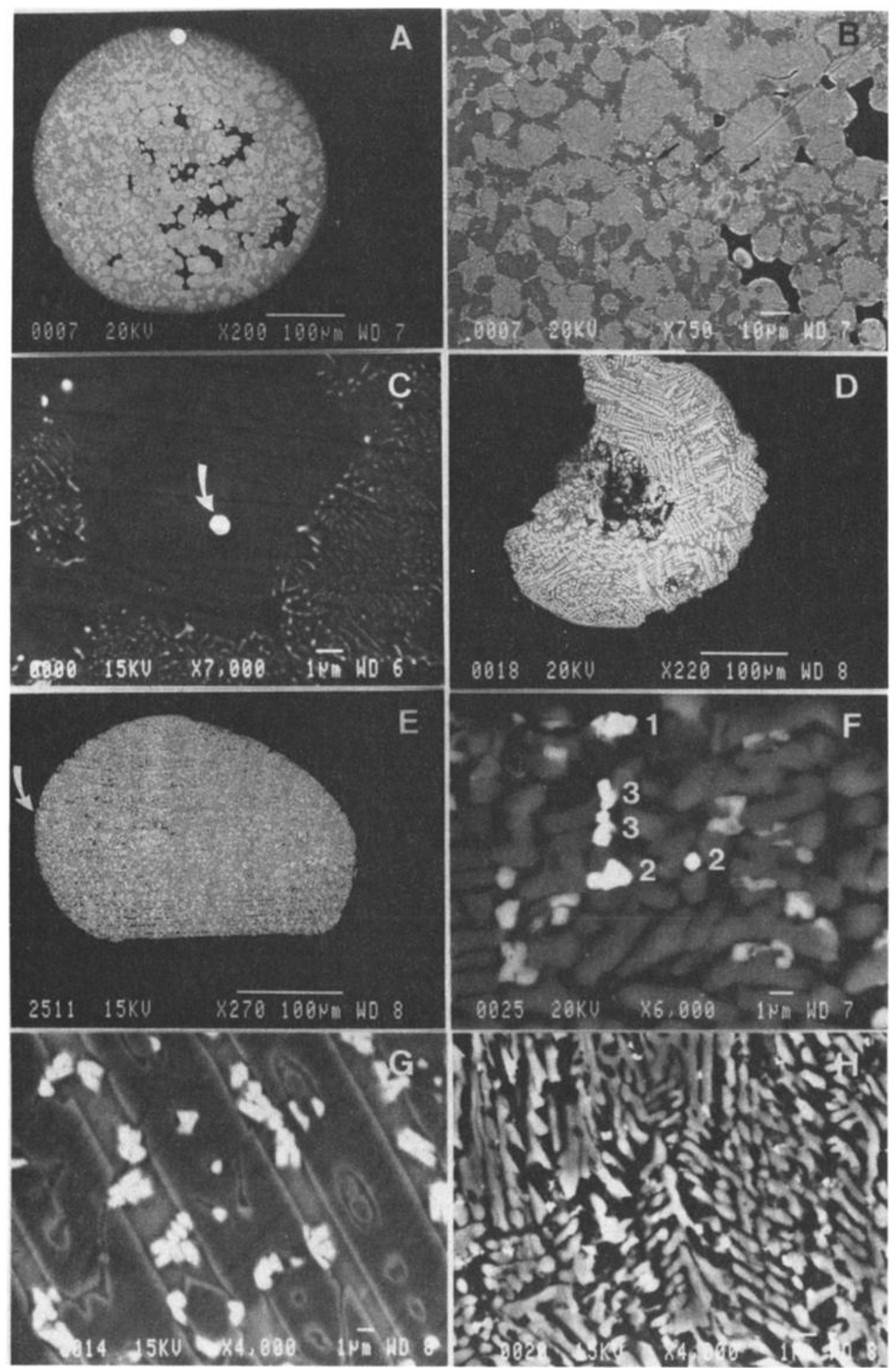

Fig. 1. SEM micrographs of polished sections of iron and chondritic deep sea spheres. (a) Ir-rich iron sphere A7: the brightest globule is a large "equilibrated" Ir-rich nugget; the darker and brighter zones refer to magnetite and wustite, respectively. (b) Same iron sphere at a higher magnification: "disequilibrated" small nuggets (see the dark arrows) dispersed in the magnetite phase. (c) Same iron sphere: this micrograph is an enlarged view of a tiny nugget showing its unexpected geometrical habit (white arrow). (d) Ir-poor iron sphere 2d: dendrites of magnetite (brightest phase) embedded in a matrix of interstitial glass (darker phase). (e) Chondritic sphere $\mathrm{CH} 25$ : the glass phase has been deeply etched out in this sphere, leaving only tiny etch canals in which the magnetite crystals are still preserved; the platinum metal nuggets shown in the next micrograph were observed in a near surface zone identified with the white arrow. $f(f)$ Same sphere at a much larger magnification: the cluster of about nine small nuggets of platinum metals can be observed as the brightest spots in this high contrast micrograph. The set of white numbers refer to the chemical group of the nuggets, as listed in Table 3. (g) Chondritic sphere CH14: a very regular "barred" texture, frequently observed in the chondritic spheres, that shows olivine lamellae (bright lamellae), interstitial glass (darker lamellae), and magnetite crystals (brightest phase). $(h)$ Chondritic sphere $\mathrm{CH} 20$ : a disordered texture of olivine and glass with a low abundance of magnetite crystals was found for this sphere. 
TABLE 1. Iron Spheres Data

\begin{tabular}{|c|c|c|c|c|c|c|c|c|c|c|c|c|c|c|c|c|}
\hline Name & la & $\mathbf{l b}$ & lc & Id & $2 \mathbf{a}$ & $2 \mathrm{c}$ & 2d & A3 & $4 \mathbf{a}$ & $4 b$ & A5 & A6 & A7 & A8 & A11 & A14 \\
\hline \multicolumn{17}{|c|}{ Energy Dispersive $X$ ray Analysis* } \\
\hline $\mathrm{Mg} \%$ & & & & 3.5 & 0.6 & & 1.6 & & & & & & & & & \\
\hline $\mathrm{Al} \%$ & & & & 0.3 & 0.2 & & 1.0 & & & & & & & & & \\
\hline $\mathrm{Si} \%$ & & 0.3 & & 4.5 & 1.0 & & 1.5 & 0.2 & & & & & & & & \\
\hline $\mathrm{Ca} \%$ & & 0.2 & & 0.6 & & & & & & & & & & & & \\
\hline Ti\% & & & & & & & 0.7 & & & & & & 0.9 & & & \\
\hline $\mathrm{Cr} \%$ & 0.2 & & & 0.2 & & & 0.6 & & & & & & & 0.2 & & \\
\hline $\mathrm{Fe} \%$ & 66.6 & 70.3 & 67.3 & 57.8 & 65.4 & 67.8 & 62.1 & 70.0 & 70.2 & 70.9 & 67.7 & 71.1 & 62.2 & 68.6 & 67.3 & 69.8 \\
\hline $\mathrm{Co} \%$ & 0.4 & 0.5 & 0.6 & 0.4 & 0.3 & & 0.5 & & 0.4 & 0.3 & 0.5 & & 0.6 & 0.6 & 0.2 & 0.5 \\
\hline $\mathrm{Ni} \%$ & 5.6 & 1.1 & 4.6 & 2.0 & 4.4 & 4.9 & 2.9 & 2.3 & 1.9 & 1.3 & 4.6 & 1.4 & 9.2 & 3.3 & 5.3 & 2.3 \\
\hline \multicolumn{17}{|l|}{ Weight ${ }^{\dagger}$} \\
\hline$\mu \mathrm{g}$ & 58 & 102 & 13 & 98 & 15 & 16 & 70 & 178 & 218 & 84 & 137 & 121 & 246 & 34 & 193 & 98 \\
\hline \multicolumn{17}{|l|}{ INAA Data ${ }^{\ddagger}$} \\
\hline Sc ppm & $<0.4$ & $<0.6$ & $<0.7$ & 1.4 & $<0.6$ & $<1.1$ & 7.3 & $<0.1$ & $<0.1$ & $<0.2$ & $<0.3$ & $<0.1$ & 1.1 & $<0.3$ & $<0.2$ & $<0.3$ \\
\hline $\mathrm{Ni} \%$ & 4.9 & 1.3 & 5.7 & 2.5 & 4.7 & 6.7 & 2.7 & 2.2 & 7.7 & 1.3 & 4.3 & 1.5 & 8.9 & 3.2 & 5.4 & 2.0 \\
\hline Co ppm & 2460 & 2400 & 3910 & 3000 & 3240 & 3180 & 2180 & 1820 & 3030 & 2350 & 3320 & 2600 & 5140 & 3410 & 2210 & 2580 \\
\hline Cr ppm & & & & & & & 8300 & 266 & & & 96 & 277 & 1000 & 1900 & 1800 & 570 \\
\hline $\begin{array}{l}\text { Ir ppm } \\
\text { Residual } \mathrm{Ir}^{\S}\end{array}$ & 11.6 & 7.0 & 4.2 & 2.1 & $<0.1$ & 6.7 & $<0.04$ & $\begin{array}{l}12.3 \\
0.27\end{array}$ & $\begin{array}{r}4.1 \\
<0.04\end{array}$ & 11.0 & 5.1 & 10.1 & 73.0 & 7.2 & 5.6 & $\begin{array}{r}5.2 \\
<0.4\end{array}$ \\
\hline Wustite & $\mathbf{x}$ & $\mathrm{x}$ & $\mathrm{x}$ & & $\mathbf{x}$ & $x$ & & $\mathbf{x}$ & $\mathrm{x}$ & $\mathbf{x}$ & $\mathbf{x}$ & $x$ & $x$ & $x$ & $x$ & $x$ \\
\hline Magnetite & $\mathbf{x}$ & $\mathbf{x}$ & $\mathbf{x}$ & $\mathbf{x}$ & $\mathbf{x}$ & $\mathbf{x}$ & $\mathbf{x}$ & $\mathbf{x}$ & $\mathbf{x}$ & $\mathbf{x}$ & $\mathbf{x}$ & $\mathbf{x}$ & $\mathbf{x}$ & $\mathbf{x}$ & $\mathbf{x}$ & $\mathbf{x}$ \\
\hline Glass & & & & $\mathbf{x}$ & $\mathbf{x}$ & & $\mathrm{x}$ & & & & & & & & & \\
\hline Ni Segregation & $\mathbf{x}$ & & $\mathbf{x}$ & & & & & & & & $\mathbf{x}$ & & $\mathbf{x}$ & $\mathbf{x}$ & & \\
\hline $\begin{array}{l}\text { Disequilibrated } \\
\text { Nuggets }\end{array}$ & & & & & & & & $\mathbf{x}$ & & $\mathrm{x}$ & & & $\mathrm{x}$ & & & \\
\hline
\end{tabular}

*Values below 0.2 are not considered.

${ }^{\dagger}$ Calculated from EDS analysis (Fe content) and INAA (weight of iron).

$\ddagger$ Chromium was not detectable because of the long delay between irradiation and counting.

$\S_{\text {After removing major nuggets. }}$

rays of ${ }^{192} \mathrm{Ir},{ }^{51} \mathrm{Cr},{ }^{59} \mathrm{Fe},{ }^{58} \mathrm{Co},{ }^{46} \mathrm{Sc}$, and ${ }^{60} \mathrm{Co}$ were measured with an HP Ge detector (FWHM $1.8 \mathrm{keV}$ at $1332 \mathrm{keV}$; relative efficiency: 20\%). For each sphere these $\gamma$ ray lines can be related to the absolute weights of $\mathrm{Ir}, \mathrm{Cr}, \mathrm{Fe}, \mathrm{Ni}, \mathrm{Sc}$, and $\mathrm{Co}$, respectively, by means of the standards (INAA results in Tables 1 and 2). Second, about $20 \%$ to $30 \%$ of each sphere was ground off, and a new counting was performed that yielded the residual weights of each element. Then each polished section was studied with a JEOL JSM-840 scanning electron microscope equipped with both two solid-state detectors for Z-contrast image and a LINK energy dispersive $X$ ray spectrometer for quantitative elemental analyses. Major element compositions were thus determined on a large $(50 \mu \mathrm{m} \times 50 \mu \mathrm{m})$ surface. With appropriate standards, the accuracy of the analyses varied from $1 \%$ to $30 \%$,

TABLE 2. Chondritic Spheres Data

\begin{tabular}{|c|c|c|c|c|c|c|c|c|}
\hline Name & $\mathrm{CH} 10$ & $\mathrm{CH} 12$ & $\mathrm{CH} 13$ & $\mathrm{CH} 14$ & $\mathrm{CH} 20$ & $\mathrm{CH} 21$ & $\mathrm{CH} 24$ & $\mathrm{CH} 25$ \\
\hline \multicolumn{9}{|c|}{ Energy Dispersive Analysis* } \\
\hline $\mathrm{Mg} \%$ & 15.9 & 8.0 & 20.0 & 16.2 & 24.3 & 20.9 & 14.4 & 14.3 \\
\hline $\mathrm{Al} \%$ & 1.3 & 3.8 & 0.7 & 1.0 & 1.7 & 1.6 & 1.2 & 1.5 \\
\hline $\mathrm{Si} \%$ & 19.9 & 8.6 & 16.4 & 17.8 & 16.4 & 17.7 & 11.9 & 17.2 \\
\hline $\mathrm{Ca} \%$ & 2.1 & 0.2 & 0.5 & 1.7 & & 1.4 & 0.2 & 1.5 \\
\hline Ti\% & & 0.5 & & & & & & \\
\hline $\mathrm{Cr} \%$ & 0.3 & 0.5 & & 0.4 & & 0.3 & 0.6 & 0.3 \\
\hline Mn\% & 0.4 & & & & 0.6 & 0.3 & 0.3 & 0.6 \\
\hline $\mathrm{Fe} \%$ & 17.8 & 42.9 & 21.4 & 21.9 & 14.8 & 15.7 & 33.9 & 24.1 \\
\hline \multicolumn{9}{|l|}{ Weight $t^{\dagger}$} \\
\hline$\mu \mathrm{g}$ & 327 & 113 & 180 & 214 & 141 & 174 & 125 & 162 \\
\hline \multicolumn{9}{|c|}{ INAA Data } \\
\hline Sc ppm & 9.9 & 9.4 & 5.4 & 8.2 & 4.6 & 8.8 & 4.8 & 6.1 \\
\hline Ni ppm & 2730 & 3340 & 1960 & 12000 & 400 & 2440 & 10300 & 6280 \\
\hline Co ppm & 120 & 400 & 330 & 450 & 26 & 300 & 530 & 300 \\
\hline Cr ppm & 1970 & 4250 & 990 & 3950 & 540 & 1850 & 4520 & 2200 \\
\hline Ir ppb & 10 & 2970 & 54 & 353 & 220 & 378 & 374 & 296 \\
\hline
\end{tabular}

*Values below 0.2 are not considered.

${ }^{\dagger}$ Calculated from EDS analysis (Fe content) and INAA (weight of iron). 
depending on elemental concentration (LINK results in Tables 1 and 2). From the Fe concentrations we calculated the weight of each sphere and then all minor element concentrations using INAA results. Third, some spheres were next sequentially polished in order to remove micrometer-thick layers from their surface. Gamma ray measurements of Ir, Co, and Fe conducted after each polishing step yielded the "depth profiles" of the residual weight of each element. Simultaneously, many SEM and EDS observations were made during this tedious polishing procedure, including specific observations of the one polished section that did show a discontinuity in the Ir profile (we show below that this section does in fact intersect an Ir-rich nugget). Finally, a few spheres were further polished for determining whether any residual iridium remained when all the nuggets had been removed.

\section{INAA RESULTS}

\section{Iridium Concentrations}

With the exception of two iron spheres in which iridium was below our detection limit (indicated as upper limits in Table 1), all iron and chondritic spheres found in the size fraction investigated in this work show a peculiar clustering of high iridium concentrations before polishing. These high iridium contents confirm an extraterrestrial origin, which was already demonstrated for similar types of spheres of a slightly larger size $(\sim 500 \mu \mathrm{m})$ by very difficult measurements of their ${ }^{26} \mathrm{Al}$ and ${ }^{10} \mathrm{Be}$ concentrations [Raisbeck et al., 1984, 1985, 1986; Yiou et al., 1985]. In the 14 iron spheres in which Ir was detectable, 13 spheres yielded iridium concentrations that are very narrowly clustered within a factor of $6(2.1$ to $12.3 \mathrm{ppm})$ and one sphere gave a much higher value (73 ppm). In the set of eight chondritic spheres, five spheres gave values $(220,296,353,374$, and 378 ppb) that are close to that (473 ppb) quoted for the $\mathrm{C} 1$ chondrite Orgueil [Anders and Ebihara, 1982], and only three spheres departed from this trend in showing either lower (10 and 54 $\mathrm{ppb})$ or higher $(2970 \mathrm{ppb})$ iridium concentrations.

\section{Element Fractionation}

Using our INAA results (Tables $I$ and 2) and data for the Orgueil meteorite, we represent each sphere on a $K(X / Y)=$ $(X / Y) /(X / Y)$ o diagram where our value, $X / Y$, of the concentration ratio (in mass) of elements $X$ and $Y$ is stated relative to Orgueil (subscript o). In this paper we only report on a semilogarithmic scale the abundance ratios obtained for $\mathrm{X}=\mathrm{Ir}, \mathrm{Co}, \mathrm{Ni}, \mathrm{Cr}$, and $\mathrm{Sc}$ in the iron and chondritic spheres, by choosing iron as the reference element $\mathrm{Y}$.

Ir-rich iron spheres (Figure 2a). For the 14 Ir-rich spheres, Ir is enriched $(K=1.5-50)$ with regard to $\mathrm{Co}$ and $\mathrm{Ni}$, which show only small variations around the normal chondritic ratio. The two lithophile elements ( $\mathrm{Cr}$ and $\mathrm{Sc}$ ) are strongly depleted, and this trend seems to be more pronounced for $\mathrm{Sc}\left(\mathrm{K}<8.10^{-2}\right)$ than for $\mathrm{Cr}\left(1.10^{-2}<\mathrm{K}<2.10^{-1}\right)$. The lack of $\mathrm{Cr}$ measurements for eight spheres is due to the long delay between irradiation and counting.

Chondritic spheres (Figure 2b). While abundance ratios for Ir are widely scattered, the other siderophile elements $(\mathrm{Co}, \mathrm{Ni})$ show a roughly similar depletion pattern with $\mathrm{K}(\mathrm{X} / \mathrm{Fe})$ ranging from $4.5 \times 10^{-2}$ to about 0.9 . The two lithophile elements $(\mathrm{Cr}$ and $\mathrm{Sc}$ ) have normal abundance ratios ranging from about 0.45 up to 1.8, with $\mathrm{Cr}$ showing the trend of being slightly depleted with regard to Sc. Sphere CH14 is clearly chondritic with the five abundance ratios near 1.
Ir-poor iron spheres (Figure 2a). Their different depletion patterns are still related to those of the other spheres, as one of them (sphere 2a) looks similar to that of the Ir-rich iron spheres, while the other one (sphere $2 \mathrm{~d}$ ) rather fits the trend observed for the chondritic spheres.

\section{The Ir Depth Profiles and the Hunt for Platinum Metal Nuggets}

For all Ir-rich spheres, the $\gamma$ ray measurements both before and after the first major single polishing step that leaves $70 \%$ to $80 \%$ of the initial mass show generally two distinct evolutions for Ir: Either Ir weight is unaffected upon polishing (Figure $3 a$ ), or this element is no longer detectable. This fast initial step of the polishing procedure already indicates that Ir is always concentrated in a discrete phase (i.e., "nugget") and not homogeneously dispersed in the host spheres.

For the spheres showing no Ir loss, this first step was followed up by the tedious sequential polishing, which could only be applied to a few spheres so far. We thus observed that Ir shows a depth profile different from that of the other elements, represented by $\mathrm{Co}$ in Figures $3 a$ and $3 b$. While the weight of Co steadily decreases upon polishing, that of Ir first keeps a constant value and then undergoes a sharp discontinuity. These depth profiles indicate that $\mathrm{Ir}$ is concentrated in tiny Ir-rich nuggets. They also give an important guideline for finding these nuggets with the SEM. Indeed, as long as the Ir plateau is observed, the nuggets are still below the polished section; but when a partial discontinuity is observed, this indicates a nugget is intersecting the polished section of the sphere, having been partially ground away. Such a section was carefully examined with the SEM for nuggets and when a nugget is found, it is analyzed by EDS.

These Ir depth profiles show that nuggets are much more frequently formed in cosmic spheres than previously thought. Indeed, the existence of nuggets of platinum metals in iron spheres was already directly inferred from SEM observations by Brownlee et al. [1984]. These authors found that about half the iron spheres contain a single platinum metal nugget with sizes of 5-10 $\mu \mathrm{m}$, and that in their examination of polished sections of $\sim 1000$ chondritic spheres no nugget was observed. All of the $14 \mathrm{Ir}$-rich iron spheres investigated in our work contain at least one nugget, and sphere A7 with 73 ppm of iridium shows two nuggets (Figure $3 b$ ). In addition, the initial part of the Ir profiles indicates that nuggets also exist in each one of the 8 chondritic spheres analyzed so far, and we succeeded in finding them in sphere CH25 (Figures le and 1f). We also show below from direct SEM observations that both types of spheres contain new families of smaller platinum metal nuggets that are frequently depleted in Ir and are thus not detectable in the Ir profiles (Figure 1c). We finally infer that iridium (and probably the other platinum metals) has been very efficiently collected in most of the Ir-rich nuggets, as this element cannot be detected in the spheres after the loss of their platinum metal nugget. However, in one iron sphere (A3 in Table 1) we still detected about $2 \%$ of the initial mass of Ir after the removal of its major nugget.

\section{SEM OBSERVATIONS AND EDS ANALYSES}

\section{Microstructure of the Spheres}

Fourteen iron spheres show a rather similar structure. In these spheres, magnetite $\left(\mathrm{Fe}_{3} \mathrm{O}_{4}\right)$ and wustite $(\mathrm{FeO})$ are the two major 


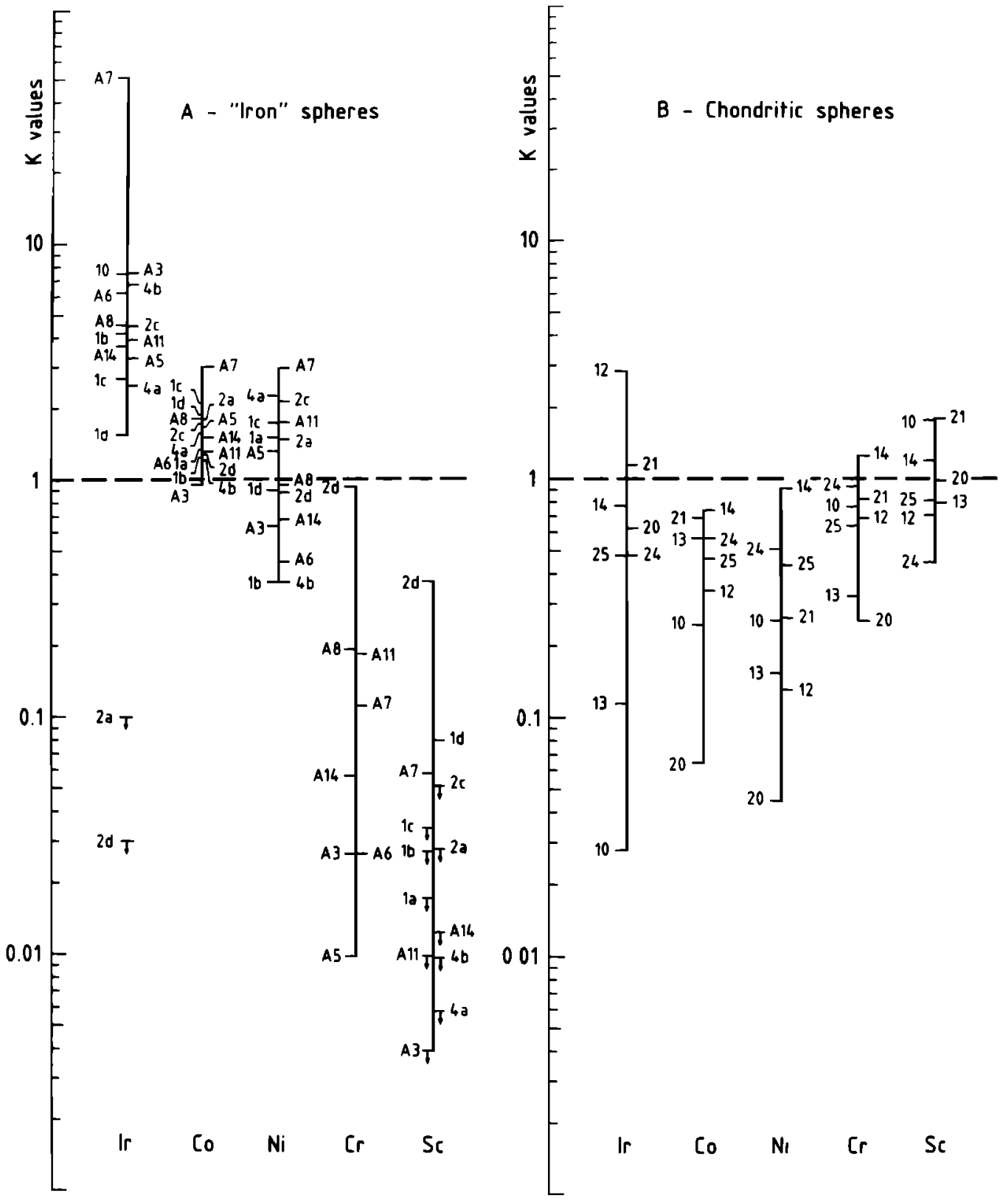

Fig. 2. Fractionation patterns noted for $\mathrm{Ir}, \mathrm{Co}, \mathrm{Ni}, \mathrm{Cr}$, and $\mathrm{Sc}$ in $(a) 16$ iron and (b) 8 chondritic deep sea spheres. $K$ values represent the abundance ratio: $K=(\text { element } / \mathrm{Fe})_{\text {sphenut }} /(\text { element } / \mathrm{Fe})_{\text {orguel. }}$. Upper limits in the concentrations of Ir and $\mathrm{Sc}$ in the iron spheres have been reported as downward arrows.

phases, and no chondritic material can be directly observed with the SEM. The nature of these phases was determined in one sphere from Debye-Scherrer $X$ ray diffraction patterns. We found that wustite always contains a higher concentration of $\mathrm{Ni}$ than magnetite by factors of 1.3 up to 2 . Both phases are clearly separated on SEM micrographs, with wustite appearing as the brighter phase (Figures $1 a$ and $1 b$ ) as a result of a higher average atomic number. The grain boundaries between the two phases contain frequently very tiny and needle-shaped segregations of $\mathrm{Ni}$ (Figure lc).

The chondritic spheres are generally made of olivine crystals and interstitial residual glass that contains a variable amount of tiny magnetite crystals (Debye-Scherrer patterns). The spheres show diverse structures that range from a well-ordered barred texture (Figure $1 \mathrm{~g}$ ), dominated by long and relatively large olivine lamellae separated by interstitial glass loaded with magnetite crystals, to the extreme example of the highly disordered and magnetite-poor structure found in sphere $1 d$ (Figure $1 h$ ).

Three spheres that were initially classified as iron spheres are rather "stony iron" objects somewhat intermediate between these two major classes of deep sea spheres. They all contain a minor fraction of $\mathrm{Mg}, \mathrm{Al}$, and Fe-rich silicates; this is now directly observable with the SEM (see the darker minor phase in Figure $1 d$ ). Two of them (spheres $1 d$ and $2 d$ ) show only a single oxidized phase of $\mathrm{Fe} / \mathrm{Ni}$ alloys, which gives a good example of dendritic growth (Figure $1 d$ ). The third sphere (2a) exhibits a unique "intestine"-folded configuration of magnetite and wustite. Sphere 2d (Figure $1 d$ ) was broken before counting. This might explain its low Ir concentration if the nugget was embedded in the lost broken fragment. 

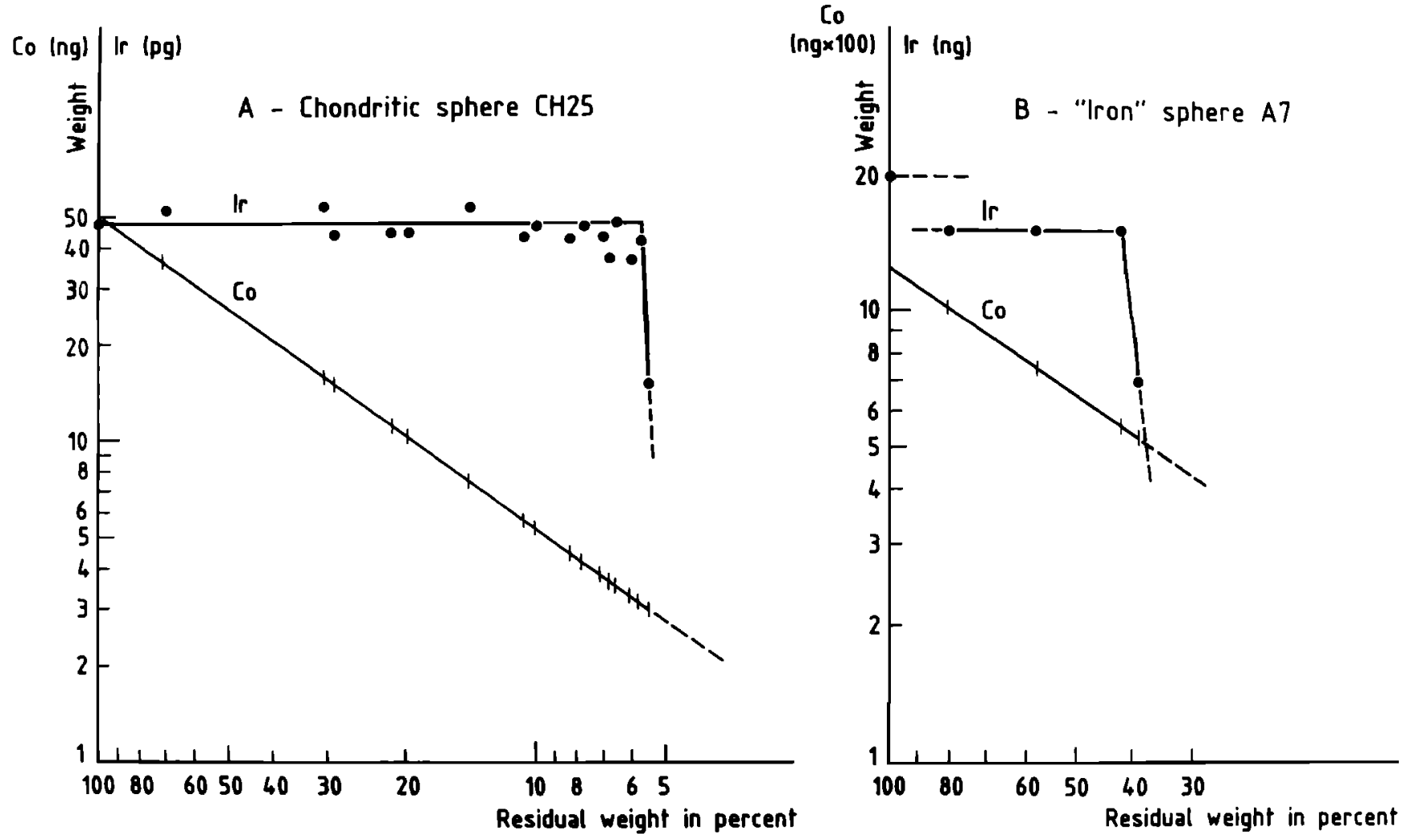

Fig. 3. Depth profiles of ${ }^{192}$ Ir and ${ }^{60} \mathrm{Co}$. (a) For the chondritic sphere $\mathrm{CH} 25$ the initial weight of iridium did not change during the first polishing step, and a cluster of nuggets (Figure $1 f$ intersected the polished section when $-95 \%$ of the mass of the sphere was ground away. (b) For the iron sphere A7, a nugget was completely lost during the first polishing step, and a second nugget (Figure 1a) was found on the surface when $-60 \%$ of the mass of the sphere had been ground away.

\section{Platinum Metal Nuggets in Four Iron Spheres and One Chondritic Sphere}

In the Ir-rich iron spheres the SEM and EDS analyses define three major groups of nuggets. We found the two families of "large" nuggets previously observed by others: (1) large globules, with diameters of $-50 \mu \mathrm{m}$ of almost pure nickel [Brownlee, 1981], that we found to be real platinum metal nugget (lines 1 and 2 in Table 3) containing all the Ir of the spheres; and (2) Ir-rich spherical nuggets (Figure $1 a$ ), with smaller sizes of
5 and $20 \mu \mathrm{m}$, that were first reported by Brownlee et al. [1984] and that show the typical "equilibrated" compositions reported in lines 3 and 4 in Table 3. But we also found a new family of micrometer- and submicrometer-sized nuggets showing specific properties. They are abundant (Figure $1 b$ ), always found in the magnetite phase, and some have a geometrical habit (Figure 1c). Moreover, they all show a "disequilibrated" composition (lines 5 and 6 in Table 3 ) in that they only contain the most volatile $\mathrm{Pt}$-metals ( $\mathrm{Pt}, \mathrm{Ru}$, and $\mathrm{Rh}$ ). These small nuggets cannot be generally revealed from the Ir-profiles, as they are

TABLE 3. Platinum Metal Compositions of Nuggets

\begin{tabular}{|c|c|c|c|c|c|c|c|c|}
\hline $\begin{array}{l}\text { Element } \\
\text { (Wt \%) }\end{array}$ & $\mathrm{Fe}$ & $\mathbf{N i}$ & Os & Ir & $\mathbf{R u}$ & $\mathbf{P t}$ & $\mathbf{R h}$ & $\mathbf{P d}$ \\
\hline $\begin{array}{l}\text { Iron Spheres } \\
\text { 4a Ni globule } \\
\text { 2c Ni globule }\end{array}$ & $\begin{array}{r}10.1 \\
8.2\end{array}$ & $\begin{array}{l}88.8 \\
91.2\end{array}$ & & $\begin{array}{l}0.006^{*} \\
0.2^{*}\end{array}$ & & & & \\
\hline $\begin{array}{l}\text { A8 nugget } \\
\text { A7 nugget }\end{array}$ & $\begin{array}{l}3.1 \\
5.9\end{array}$ & $\begin{array}{l}9.0 \\
4.2\end{array}$ & $\begin{array}{l}21.7 \\
28.8\end{array}$ & $\begin{array}{l}19.5 \\
18.4\end{array}$ & $\begin{array}{l}16.6 \\
14.6\end{array}$ & $\begin{array}{l}27.1 \\
25.8\end{array}$ & $\begin{array}{l}2.8 \\
2.3\end{array}$ & \\
\hline $\begin{array}{l}\text { A3 small nugget } \\
\text { A7 small nugget }\end{array}$ & $\begin{array}{l}28{ }^{\dagger} \\
22.4^{\dagger}\end{array}$ & $\begin{array}{l}21 \\
20.8\end{array}$ & & & $\begin{array}{l}2.1 \\
3.5\end{array}$ & $\begin{array}{l}43.4 \\
44.8\end{array}$ & $\begin{array}{l}4.5 \\
7.6\end{array}$ & \\
\hline $\begin{array}{l}\text { Chondritic Spher } \\
\text { Nugget } 1 \\
\text { Nugget } 2 \\
\text { Nugget } 3\end{array}$ & $\begin{array}{r}125 \\
7.0 \\
7.7 \\
3.4\end{array}$ & $\begin{array}{r}36.5 \\
2.7 \\
0.4\end{array}$ & $\begin{array}{c}<1 \\
4.2 \\
61.8\end{array}$ & $\begin{array}{r}5.5 \\
19.5 \\
20.2\end{array}$ & $\begin{array}{l}11.9 \\
25.4 \\
10.5\end{array}$ & $\begin{array}{r}25.6 \\
38.4 \\
2.7\end{array}$ & $\begin{array}{l}4.0 \\
1.7\end{array}$ & 8.4 \\
\hline
\end{tabular}

Energy dispersive $\mathrm{X}$ ray analysis; values below 0.2 are not considered.

*Calculated from INAA data and globule diameter.

†Partially due to the matrix. 
depleted in this element. All types of nuggets in the iron spheres are associated with the magnetite and not with the wustite phases.

In the chondritic sphere $\mathrm{CH} 25$ a cluster of at least nine micrometer-sized nuggets was discovered near the deeply weathered top surface of this sphere after removing $95 \%$ of its mass (see the white arrow in Figure 1e). Each nugget exhibits a specific composition that is highly disequilibrated and that looks different from those noted for the disequilibrated small nuggets in the iron spheres. In particular, an unexpectedly high concentration of palladium (a highly volatile platinum group element) was found in nugget 1 (line 7 in Table 3). The compositions of the other nuggets have been tentatively classified in two additional chemical groups that are listed in lines 8 and 9 in Table 3. The nuggets again seem to be associated with the segregations of magnetite. Indeed, with the exception of their higher " $Z$ " brightness on SEM micrographs, they look rather similar to the magnetite crystals, with regard to both their preferential localization in the constituent interstitial glass of the spheres and their size and geometrical habit (Figure 1 $f$ ). In a deep sea chondritic sphere, F. Kyte (personal communication, 1986) found one nugget containing all six platinum metals. We note that the bulk analysis of the cluster of nuggets found in $\mathrm{CH} 25$ would give a rather similar composition.

\section{Discussion}

\section{Correlations Between Microstructure and Chemical Composition}

Thirteen Ir-rich iron spheres present the typical texture of wustite and magnetite reported in Figures $1 a$ and $1 b$. Three types of distribution of platinum metals can be observed: They can be concentrated in a single big Ni-core (4a), in one or two nuggets (A3), and in small "disequilibrated" nuggets (A3, 4b, and A7). The existence of a large Ni-core in sphere $4 a$ accounts for the different Ni concentrations determined by INAA or EDS (Table 1). All spheres in this group are strongly depleted in $\mathrm{Cr}$ and Sc (Figure 2a).

Two other iron spheres (1d and 2d) with a dendritic texture (Figure $1 d$ ) show the least depleted composition in lithophile elements. This is related to the existence of a minor glassy phase. They are probably the G-type spherules classified by Blanchard et al. [1980].

A correlation between microstructure and chemical composition is not found in the chondritic spheres. For example, spheres $\mathrm{CH} 14$ and $\mathrm{CH} 20$ show very different textural features (Figures $1 g$ and $1 h$ ) that correspond to two different depletion patterns, but their iridium content is similar (Figure $2 b$ ).

\section{Constraints on the Origin of the Ir-rich Cosmic Spheres}

It was previously argued that iron spheres originate from a process of $\mathrm{Fe} / \mathrm{Ni}$ globule ejection from a chondritic melt [Brownlee et al., 1984]. Brownlee [1981] found small $(<50 \mu \mathrm{m}$ sized) globules in the near-surface region of a few chondritic spheres and/or small cavities with similar shapes and sizes. These were interpreted to result from the ejection of the $\mathrm{Fe} / \mathrm{Ni}$ globules from a parent chondritic melt formed upon ablation in the atmosphere. The lost globules were postulated to form iron cosmic spheres.

Yiou et al. [1985] recently proposed a quite different origin for the iron spheres. They measured saturation values for the concentrations of ${ }^{10} \mathrm{Be}$ (a strongly lithophile element) in five iron spheres (size $\sim 500 \mu \mathrm{m}$ ) that are similar to saturation values measured for iron meteorites. This shows that iron spheres with sizes only slightly larger than those investigated in our work can only originate from an iron-rich body and not from a chondritic melt that should have kept the strongly lithophile element.

In deep sea sediments the abundance of the iron spheres with sizes $>100 \mu \mathrm{m}$ is roughly similar to that of the chondritic spheres in the same size range [Brownlee, 1981]. Consequently, if each one of the chondritic spheres ejects one iron sphere on the average, we should have found a high depletion of iron and iridium, as well as no platinum metal nugget in the chondritic spheres. As these trends were not observed, we believe that the conclusion of Yiou et al. [1985] about the formation of the iron spheres from Fe-rich bodies also extends to the slightly smaller size fraction investigated in the present work.

There is possibly additional information in the depletion pattern of other trace elements. For example, such bodies would show a much narrower range of Ir concentrations than that observed in iron meteorites, which covers 4 orders of magnitude range [Mason, 1971]. Moreover, if iron spheres did originate from iron meteorites and not from pallasites, the concentrations of $\mathrm{Cr}$ and $\mathrm{Sc}$ should have been about 100 times smaller than the values reported here. Therefore the iron-rich parent bodies of the spheres are probably different from iron meteorites in that they contain a minor fraction of chondritic material. This conclusion applies particularly to spheres $1 d$ and $2 d$, which not only yield the highest concentrations of Sc but also show direct evidence with the SEM for a silicate phase (Figure $1 d$ ).

\section{Summary and Future Prospects}

Platinum metal nuggets are much more frequently formed in both iron and chondritic deep sea cosmic spheres than previously thought. Their formation process is still poorly understood. On the one hand, the large "equilibrated" nuggets have likely been formed by a single process, such as settling in a molten phase formed upon ablation in the atmosphere. However, this process of segregation must be extremely efficient and fast, in order to collect all Ir initially present in the parent bodies of the spheres over the short thermal pulse that they experience during the ablation process. Furthermore, this single process is not expected to yield the highly disequilibrated family of nuggets reported here. Indeed, both results are hard to reconcile with usual concepts of "classical" metallurgy (A. Lesoulte, personal communication, 1986).

For the iron spheres our measurements would also extend to a slightly smaller size fraction the earlier conclusions of Yiou et al. [1985], pertaining to the existence of iron-rich parent bodies for the iron spheres. Correlations between microstructure and minor and trace element fractionation in individual cosmic spherules should soon yield additional clues about such parent bodies, when we consider other important trace elements such as $\mathrm{Au}$ and $\mathrm{W}$.

However, these preliminary inferences are based on several assumptions that still have to be checked. In particular, we assume that the initial concentrations of platinum metals in the parent bodies of the Ir-rich spheres have not been strongly modified during the short pulse heating occurring during their ablation in the atmosphere. As emphasized by F. Kyte in his careful review of our manuscript, these key assumptions are yet unproven. Fortunately they should soon be checked by conducting simulation experiments with solar furnaces at Odeillo, with materials including chunks of chondritic and iron 
meteorites, such as Mighei and Negrillos, in which the sequential polishing technique revealed an homogeneous distribution of iridium. The new facilities available there can now deliver thermal pulses with a minimum duration of about $0.1 \mathrm{~s}$, which are much shorter than those previously used by King [1982] at the same facilities for investigating the formation of chondrules. Moreover, the experiments can be conducted in a controlled atmosphere, in which the residual pressure of atomic oxygen can be correctly adjusted so as to assess the possible role of this important atomic species in the ablation "metallurgy" that reprocessed the cosmic spheres from still poorly known parent bodies.

Acknowledgments. We thank F. Kyte for his excellent and very helpful review of this manuscript and G. Raisbeck for very useful comments. This work was mostly supported by two grants from "Action Thématique Programmée de Planétologie" from INSU as well as by fundings from CEA and CNRS. This is CFR contribution No. 794.

\section{REFERENCES}

Anders, A., and M. Ebihara, Solar system abundances of the elements, Geochim. Cosmochim. Acta, 46, 2363-2380, 1982.

Blanchard, M. B., D. E. Brownlee, T. E. Bunch, P. W. Hodge, and F. T. Kyte, Meteorite ablation spheres from deep-sea sediments, Earth Planet. Sci. Lett., 46, 178-190, 1980.

Brownlee, D. E., Extraterrestrial components in deep sea sediments, in The Sea, vol. 7, edited by C. Emiliani, pp. 733-762, Wiley, New York, 1981.

Brownlee, D. E., B. A. Bates, and M. Wheelock, Extraterrestrial platinum group nuggets in deep sea sediments, Nature, 309, 693695, 1984.

Ganapathy, R., The Tunguska explosion of 1908: discovery of meteoritic debris near the explosion site and at the South Pole, Science, 220, $1158-1161,1983$.

King, E. A., Refractory residues, condensates and chondrules from solar furnace experiments (abstract), in Lunar and Planetary Science XIII, pp. 389-390, Lunar and Planetary Institute, Houston, 1982.

Mason, B., Handbook of Elemental Abundances in Meteorites, Gordon and Breach, New York, 1971.

Raisbeck, G. M., F. Yiou, J. Klein, Y. Yamakoshi, and D. E. Brownlee, ${ }^{26} \mathrm{Al}$ and ${ }^{10} \mathrm{Be}$ in deep sea stony spherules; evidence for small parent bodies (abstract), in Lunar and Planetary Science XIV, pp. 622623, Lunar and Planetary Institute, Houston, 1984.

Raisbeck, G. M., F. Yiou, J. Klein, R. Middleton, and D. E. Brownlee, ${ }^{26} \mathrm{Al} /{ }^{10} \mathrm{Be}$ in deep sea spherules as evidence of cometary origin, in Properties and Interactions of Interplanetary dust, edited by R. H. Giese and P. Lamy, pp. 169-174, D. Reidel, Dordrecht, 1985.

Raisbeck, G. M., F. Yiou, D. Bourles, and M. Maurette, ${ }^{10} \mathrm{Be}$ and ${ }^{26} \mathrm{Al}$ in Greenland cosmic spherules; Evidence for a cometary origin, Sixth Int. Conf. Geochronology. Cosmochronology and Isotope Geology, Cambridge, in press, 1986.

Yamakoshi, K., Further studies on size distribution of siderophile elements concentrations in black magnetic spherules from deep sea sediments, J. Geomag. Geoelectr., 37, 205-213, 1985.

Yiou, F., G. M. Raisbeck, and D. E. Brownlee, ${ }^{10} \mathrm{Be}$ in iron type cosmic spherules: Evidence for a differentiated parent body, Meteoritics, 20 , 791-792, 1985

Ph. Bonté and C. Jéhanno, Centre des Faibles Radioactivités, Laboratoire Mixte CEA-CNRS, 91190 Gif-sur-Yvette, France. M. Maurette, Laboratoire René Bernas, 91406 Orsay, France.

D. E. Brownlee, Department of Astronomy, University of Washington, Seattle, WA 98195.

(Received April 22, 1986;

revised December 24, 1986;

accepted December 24, 1986.) 